\title{
PARTIDOS, ELEIÇÕES E DEMOCRACIA NO BRASIL PÓS-1985*
}

\author{
Maria D'Alva G. Kinzo
}

\section{Introdução}

É consenso que partidos políticos e eleições são componentes necessários de um regime democrático. Eleições livres e justas, nas quais os partidos competem por cargos públicos, são um critério crucial para identificar se um sistema político é uma democracia. No entanto, se a presença efetiva de partidos e eleições é reveladora de um regime democrático, somente a existência continuada de um situação democrática é que torna possível a consolidação de tais instituições. Embora evidente, essa observação é relevante no que

* Este artigo é uma versão modificada do trabalho "Parties and elections: Brazil's democratic experience since 1985", em Kinzo e Dunkerley (2003), que contou com o apoio do CNPq e da Fapesp.

Artigo recebido em março/2003

Aprovado em junho/2003 diz respeito à experiência política brasileira, uma vez que o regime militar-autoritário - que se estendeu de 1964 a 1985 - não aboliu nem os partidos nem as eleições. Certamente, sob um regime que impõe fortes restrições à participação política, esse fato não é indicativo do funcionamento efetivo desses mecanismos de representação, da mesma forma que a presença de partidos políticos e de eleições em um regime pós-autoritário, por si só, não garante a democratização desse regime.

Este artigo pretende discutir a relação entre partidos, eleições e democracia no contexto brasileiro atual. Para isso, a principal preocupação que nos move é saber em que medida o contexto democrático em vigor desde 1985 tem contribuído para a consolidação dos partidos, do sistema partidário e, conseqüentemente, da democracia no Brasil. Assim, a fim de estabelecer os parâmetros deste estudo, esclarecemos na primeira seção a maneira pela qual entendemos os termos "partidos", "elei- 
ções" e "democracia". Na segunda, o foco da análise volta-se para as eleições e seu papel de assegurar as condições mínimas de uma polity democrática. Na terceira, analisamos a experiência partidária atual, suas principais características e problemas.

\section{Democracia, eleições e partidos políticos: uma nota conceitual}

A exemplo de diversos temas analisados pelas ciências sociais, democracia é um termo complexo. Muitas obras foram produzidas para discutir seus múltiplos significados e suas implicações teóricas e empíricas. Não é nossa intenção enveredar nesse debate, o que implicaria rever uma vasta literatura. Faz-se necessário, porém, delinear uma definição neste contexto. O significado de democracia aqui empregado circunscreve-se a seu aspecto procedimental, conforme conceptualização elaborada por Schumpeter, ${ }^{1}$ o qual prioriza a capacidade analítica e empírica do conceito de identificar, no sistema político, um método específico de organização, baseado em regras e procedimentos que garantem a escolha de líderes por meio da competição política e da livre participação popular. Em outras palavras, está-se fazendo referência às duas dimensões de Dahl de poliarquia - participação e contestação pública -, cuja efetividade depende de condições livres para a manifestação e a organização política (Dahl, 1971). A ênfase na dimensão política do conceito de democracia não significa que estejamos ignorando a dimensão social como parte integrante de um contexto democrático. Não estamos negando que níveis elevados de desigualdade social possam se constituir em sério obstáculo para a plena realização da democracia. ${ }^{2}$ Como apropriadamente observou Dahl, a presença de desigualdades prejudica as possibilidades de contestação pública não apenas em função do acentuado desequilíbrio na distribuição de conhecimento e recursos políticos, como também do eventual surgimento de ressentimentos e frustrações que acabam corroendo a lealdade da população para com a democracia (Dahl, 1971).

Tomar como parâmetro a definição mais restrita de democracia, permite-nos não apenas esta- belecer, de imediato, a diferença entre um regime democrático e um não-democrático, como também reconhecer a importância, em países como o Brasil, dos avanços alcançados no processo de redemocratização, mesmo se limitados à esfera política. E é no âmbito desse significado de democracia que eleições e partidos políticos são considerados elementos fundamentais em uma polity democrática.

O papel das eleições no sistema político é aqui considerado (1) um elemento essencial no governo representativo, uma vez que a participação ou, na terminologia adotada por Dahl, a inclusão política esteja assegurada aos membros da $p o-$ lity, e (2) um meio pelo qual ganha expressão a correlação de forças dos diferentes grupos políticos, na medida em que a competição entre eles, organizados em partidos políticos, esteja garantida (a dimensão de Dahl de contestação pacífica). Eleições possibilitam não apenas a alternância de maiorias no poder, mas também a realização de dois requisitos de um governo representativo. Primeiro, representatividade, ou seja, que o Legislativo dê expressão à diversidade da polity; e segundo, responsividade, que envolve tanto a noção de um governo agindo em resposta às demandas da população, como a idéia de eficiência e competência desse governo no que diz respeito a questões que envolvem a prestação de contas à população (Sartori, 1987). Embora a representatividade possa ser assegurada pela implementação de um sistema eleitoral que permita a expressão da diversidade social e política do eleitorado em uma arena representativa, a responsividade é muito mais complexa. Sua efetividade depende, em grande parte, das condições de participação, bem como de inteligibilidade da competição eleitoral.

Com relação ao conceito de partidos políticos, apesar de seus diversos significados, é possível destacar alguns de seus traços característicos sobre os quais há um certo consenso. Em primeiro lugar, ao contexto em que os partidos atuam e, em segundo, às atividades que desenvolvem sob tal contexto. ${ }^{3}$ Os partidos têm papéis específicos em duas arenas do sistema político: a eleitoral e a decisória. Nesta última, sua atividade está associada à formulação, ao planejamento e à implementa- 
ção de políticas públicas, participando como atores legítimos no jogo de poder e no processo de negociação política. São agentes fundamentais no processo democrático representativo, pois estão respaldados no voto popular. De fato, somente com base neste critério - apoio eleitoral - é possível, no contexto das democracias de massa, falar de partidos como canais de expressão e representação de interesses, como um vínculo, ainda que frágil, entre a sociedade e o Estado. Na arena eleitoral, seu papel específico é o de competir pelo apoio dos eleitores a fim de conquistar posições de poder. É por meio desse mecanismo que a cadeia de representação política se forma nas democracias representativas, uma cadeia que vincula os cidadãos às arenas públicas de tomada de decisões.

Assim, se, de um lado, a obtenção do poder político legítimo, no contexto de um eleitorado de massas, tornou-se factível por meio da organização de partidos políticos, de outro, a representação política democrática tornou-se viável à medida que os partidos modernos, ao se constituírem como tais, assumiram as tarefas de: (1) estruturar a disputa eleitoral, ou seja, definir e diferenciar as opções a serem oferecidas ao eleitor, facilitando o ato de votar e possibilitando a construção de identidades políticas; e (2) mobilizar o eleitorado, isto é, incentivar o eleitor a ir às urnas e a votar em uma das opções oferecidas, opções que se constituem como agregações de preferências, ou seja, representação de interesses. Se, no que se refere à questão da democracia, os partidos políticos são um aspecto fundamental, é sua atividade eleitoral a que tem caráter primordial. É em função disso que a análise sobre os partidos no presente contexto democrático brasileiro aqui empreendida tem a arena eleitoral como foco principal.

\section{Eleições em um contexto democrático}

Um breve exame do panorama político brasileiro da atualidade nos permite afirmar que o regime ganhou características nítidas de uma democracia. Se tomarmos como ponto de referência as duas dimensões de poliarquia propostas por Dahl, o Brasil certamente aprimorou as condições de participação e contestação pública.
Com respeito à primeira dimensão - a da inclusão - nota-se um avanço considerável nas condições de participação política. Destaca-se, em primeiro lugar, o crescimento expressivo do número de eleitores potenciais em conseqüência da universalização do direito de voto, estabelecida com a inclusão dos analfabetos em 1985; direito que se ampliou ainda mais com a Constituição de 1988, que reduziu para 16 anos a idade mínima para votar. Como evidenciam os dados do Gráfico 1, o eleitorado brasileiro saltou de 15,5 milhões, em 1960, para 94,7 milhões, em 1994, atingindo 115 milhões, em 2002. Isso significa que, se em 1960 o eleitorado abarcava apenas 43\% da população adulta, já no início da década de 1980 a proporção quase duplicou, atingindo, em 2002, a cifra de 94\%.

\section{Gráfico 1}

Eleitorado Brasileiro 1960-2002

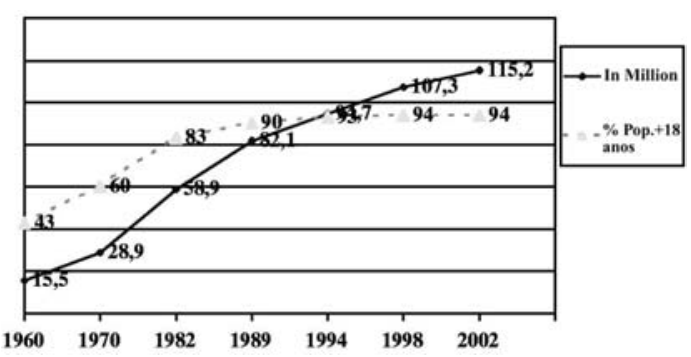

Trata-se, em segundo lugar, de um eleitorado predominantemente urbano, ou seja, a massa de eleitores residentes nas grandes cidades passou a decidir as eleições. Apesar de a maioria possuir níveis muito baixos de escolaridade e, por conseguinte, de informação política, são eleitores não mais circunscritos em pequenas cidades das zonas rurais, ambiente facilmente controlado por líderes políticos locais e onde a corrupção eleitoral era uma prática generalizada. Quanto a esse aspecto, cabe mencionar as transformações econômicas e sociais por que passou o país nas últimas três ou quatro décadas bem como suas conseqüências.

Não há dúvida de que o modelo econômico adotado pelos governos militares foi responsável, de um lado, por distorções que levaram ao agravamento da pobreza e das desigualdades sociais e re- 
gionais no Brasil; de outro, por um rápido processo de industrialização e urbanização. Esse processo resultou na inserção de um grande contingente de pessoas na arena eleitoral, ${ }^{4} \mathrm{O}$ qual, embora não plenamente integrado à sociedade, ${ }^{5}$ passou a ter um peso considerável nas eleições (às vezes, valendo-se delas para protestar contra toda sorte de privações). Resultou também no aumento substancial do contingente de trabalhadores urbano-industriais, base para a emergência de movimentos sociais e a formação de partidos de massa. Ainda que menos proeminentes do que durante os primeiros anos da democratização, os movimentos sociais urbanos são um elemento importante da nova polity democrática. No meio rural, o processo combinado de expansão capitalista no campo e preservação de formas arcaicas de produção e de propriedade da terra teve como conseqüência o agravamento do problema da exclusão social. Em contrapartida, produziu o cimento social para a intensificação do movimento pela reforma agrária que, liderado pelo MST (Movimento dos Sem Terra), tornou-se a mais importante manifestação de desobediência social no país. ${ }^{6}$ Todas essas transformações políticas e sociais são indicações relevantes da revitalização da sociedade civil e, certamente, tiveram impacto sobre o grau de inclusão da polity democrática brasileira.

Também indicativo de avanço democrático é a instauração da incerteza como traço característico do jogo político eleitoral brasileiro. Decorrência não apenas da dimensão e das características do eleitorado - que se tornou menos sujeito ao controle político de qualquer ordem -, mas também do avanço significativo das condições de livre exercício do voto. A esse respeito, vale ressaltar o papel importante desempenhado pela Justiça Eleitoral, instituição que se consolidou como garantidora da lisura do processo eleitoral. A implantação da urna eletrônica, que desde as eleições municipais de 2000 passou a ser utilizada em 100\% dos locais de votação, reduziu sobremaneira as chances de fraude eleitoral.

No que se refere à segunda dimensão de Dahl - contestação pública - os avanços foram igualmente significativos se compararmos com o período democrático entre 1945 e 1964. Nesse período a competição política era limitada não ape- nas pelo baixo grau de aceitação das regras do jogo - cujos sinais mais visíveis foram as diversas tentativas de intervenção militar -, mas também pelas restrições ao direito de a oposição competir livremente. Vale lembrar que o Partido Comunista, que entre 1945 e 1947 teve um significativo desempenho eleitoral nas áreas industriais do país, passou a ser considerado ilegal a partir de 1947 , permanecendo fora da política partidária até 1985 (Chilcote, 1982; Brandão, 1997).

Desde o restabelecimento do governo civil em 1985, o Brasil confrontou-se com uma sucessão de problemas econômicos e políticos graves, como a hiperinflação, os diversos choques econômicos, as elevadas taxas de desemprego, os escândalos de corrupção de toda sorte e, sobretudo, o impeachment de um presidente. A inexistência de qualquer tentativa de responder a essas crises ultrapassando os limites da ordem constitucional revela uma maior aceitação e, de certa forma, a consolidação das regras democráticas. Além disso, a existência de organizações políticas, sindicatos e movimentos sociais com orientação ideológica ou base social diversas evidencia uma maior tolerância com a oposição. O mesmo se pode dizer em relação à incorporação, no sistema político, dos partidos de esquerda - hoje competidores reais na disputa eleitoral e partícipes efetivos no processo decisório. O exemplo mais expressivo disso é a emergência do Partido dos Trabalhadores (PT) como um dos principais competidores nas eleições, tanto em nível local e regional como nacional. Nesse aspecto, a democratização brasileira foi bastante inovadora, isto é, o restabelecimento do jogo partidário competitivo propiciou a criação de uma organização política com características típicas de um partido de massa, e cuja identidade coletiva foi construída por meio da associação dos trabalhadores assalariados com os setores organizados da sociedade civil.

Em 2000, o PT venceu a disputa para a prefeitura em seis capitais e em 29 cidades com população acima de duzentos mil habitantes. Além disso, ampliou consideravelmente sua presença em todo o país: a proporção de municípios brasileiros em que o PT saiu vencedor na disputa para o executivo municipal triplicou entre 1992 e 2000. Mesmo nas regiões em que sua participação relativa no po- 
Tabela 1

Prefeituras Conquistadas pelo PT, por Região, 1992-2000

\begin{tabular}{|c|c|c|c|c|c|c|}
\hline REGIÕES & \multicolumn{2}{|c|}{1992} & \multicolumn{2}{|c|}{1996} & \multicolumn{2}{|c|}{2000} \\
\hline & $\mathrm{N}$ & $\% *$ & $\mathrm{~N}$ & $\% *$ & $\mathrm{~N}$ & $\% *$ \\
\hline NORTE & 8 & 2,0 & 12 & 2,8 & 18 & 3,5 \\
\hline NORDESTE & 8 & 0,5 & 11 & 0,7 & 22 & 1,2 \\
\hline CENTRO-OESTE & 3 & 0,7 & 5 & 1,1 & 16 & 4,0 \\
\hline SUDESTE & 29 & 1,7 & 48 & 2,4 & 58 & 4,9 \\
\hline SUL & 9 & 0,9 & 39 & 3,4 & 58 & 4,9 \\
\hline Total & 54 & 1,1 & 115 & 2,14 & 187 & 3,4 \\
\hline
\end{tabular}

* Porcertagem sobre o total de prefeituras na região.

Fonte: Tribunal Superior Eleitoral.

der municipal era limitada, o partido obteve resultados significativos: no Nordeste, em 2000, conquistou o dobro de prefeituras em relação a 1996; no Centro-Oeste chegou a triplicar o número de prefeituras conquistadas entre 1996 e 2000 (Tabela 1).

Mais notável ainda foi o desempenho eleitoral do PT em 2002: não apenas conquistou a presidência da República com a eleição de Luis Ignácio Lula da Silva, que pela quarta vez se candidatava, como ampliou consideravelmente sua representação nas casas legislativas. Como mostram os dados da Tabela 2, o partido ocupou, em 1990, o sétimo lugar na distribuição relativa da representação na Câmara dos Deputados, e a primeira posição em 2002; no Senado, sua força relativa não cresceu da mesma forma, mas foi suficiente para deter a terceira maior representação nesta Casa.

Em suma, as condições fundamentais para o funcionamento de um sistema democrático representativo estão instauradas. Trata-se, no entanto, de

Tabela 2

Representação do PT e de outros Partidos na Câmara dos Deputados e no Senado Federal, 1990-2002 (\%)

\begin{tabular}{|c|c|c|c|c|c|c|c|c|}
\hline \multicolumn{5}{|c|}{ Câmara } & \multicolumn{4}{|c|}{ Senado } \\
\hline PARTIDO & 1990 & 1994 & 1998 & 2002 & 1990 & 1994 & 1998 & 2002 \\
\hline PT & 7,0 & 9,6 & 11,3 & 17,7 & 1,3 & 6,2 & 8,6 & 16 \\
\hline PMDB & 21,5 & 20,9 & 16,2 & 14,4 & 57,5 & 27,2 & 33,3 & 25,9 \\
\hline PSDB & 7,6 & 12,1 & 19,3 & 13,8 & 1,3 & 13,6 & 24,7 & 14,8 \\
\hline PFL & 16,5 & 17,3 & 20,5 & 16,4 & 18,7 & 22,2 & 19,8 & 23,5 \\
\hline $\mathrm{PDS} / \mathrm{PPR} / \mathrm{PPB} / \mathrm{PP}$ & 8,3 & 10,1 & 11,7 & 9,6 & 5,0 & 7,4 & 6,2 & 2,5 \\
\hline PTB & 7,6 & 6,0 & 6,0 & 5,1 & 5,0 & 6,2 & - & 2,5 \\
\hline PDT & 9,1 & 6,6 & 4,9 & 4,1 & 2,5 & 7,4 & 2,5 & 4,9 \\
\hline PSB & 2,2 & 2,9 & 3,7 & 4,3 & - & 1,2 & 3,7 & 4,9 \\
\hline PL & 3,2 & 2,5 & 2,3 & 5,1 & - & 1,2 & - & 2,5 \\
\hline $\mathrm{PCB} / \mathrm{PPS}$ & 0,6 & 0,4 & 0,6 & 2,9 & - & 1,2 & 1,2 & 1,2 \\
\hline PCDOB & 1,0 & 1,9 & 1,4 & 2,3 & - & - & - & - \\
\hline OUTROS & 15,4 & 9,7 & 2,1 & 4,3 & 19,4 & 6,2 & - & 1,2 \\
\hline TOTAL $(=100)$ & $(503)$ & (513) & (513) & (513) & (81) & (81) & (81) & (81) \\
\hline
\end{tabular}

Fonte: Tribunal Superior Eleitoral. 
saber em que medida o jogo democrático tem propiciado a realização de dois importantes princípios associados a um governo democrático: representatividade e responsividade política. Em outras palavras, é preciso analisar se o funcionamento das instituições e dos mecanismos democrático-representativos tem assegurado que o corpo de representantes seja, de alguma maneira, um retrato da sociedade, e que os governantes eleitos prestem contas à população e exerçam suas funções com responsabilidade e eficiência (Sartori, 1987).

Quanto à questão da representatividade, podemos afirmar que o sistema de representação proporcional que rege as eleições para a Câmara dos Deputados e assembléias legislativas estaduais e municipais vem garantindo, ao menos, a representação das minorias. Ademais, o amplo leque de partidos que detêm a representação nas câmaras legislativas também faz supor que o sistema político tem alcançado um elevado grau de representatividade, permitindo que todos os setores da sociedade brasileira possam ser representados. Isso a despeito de a representação proporcional, como princípio, não ser de fato plenamente respeitada. As distorções na proporcionalidade da distribuição da representação dos Estados da federação na Câmara dos Deputados foram bastante discutidas na literatura (Soares, 1971; Lamounier, 1980; Kinzo, 1980; Lima Júnior, 1993; Nicolau, 1996). E o fato de os Estados menos populosos estarem sobre-representados em detrimento dos mais populosos tem um impacto significativo na força relativa dos partidos. Ou seja, a divisão desproporcional de cadeiras por Estado faz com que a representação partidária no Congresso não reflita com precisão a força relativa dos partidos resultante das urnas, posto que o apoio eleitoral por eles obtido não é distribuído igualmente entre os Estados. Assim, partidos como o PT e o PSDB, cuja base eleitoral, ao menos até recentemente, concentrava-se nas regiões mais urbanizadas e industrializadas do Sul e Sudeste do país, acabam conquistando proporcionalmente menos cadeiras do que obteriam se o critério de proporcionalidade fosse plenamente respeitado (Nicolau, 1997).

Contudo, é em relação à responsividade que a democracia brasileira apresenta problemas mais sérios. O sistema político está longe de possuir mecanismos capazes de assegurar um grau razoável de accountability. Para isso, o sistema teria de oferecer aos eleitores (1) condições de escolha entre distintas plataformas políticas ou alternativas partidárias, e (2) uma estrutura de conexão com seus representantes, aspectos que não estão inteiramente contemplados na polity brasileira.

As instituições brasileiras pouco têm contribuído para elevar o grau de inteligibilidade do processo eleitoral. Pelo contrário, diversos fatores dificultam o exercício da cidadania, como, por exemplo, o discernimento no momento de votar. Há um complexo sistema de escolha eleitoral que envolve cargos em diferentes níveis de poder nacional, estadual e municipal - e métodos eleitorais diversos - representação proporcional para as câmaras legislativas federal, estaduais e locais, sistema de maioria simples para o Senado e sistema majoritário em dois turnos para presidente e governadores. Além disso, por ser um sistema de representação proporcional com lista aberta, as eleições para deputados federais e estaduais são primordialmente uma disputa entre candidatos individuais. E ainda, o grande número de partidos dispostos a enfrentar a disputa eleitoral em distritos de grande magnitude ${ }^{8}$ resulta em um excesso de candidatos, o que torna as opções menos nítidas para os eleitores. As regras eleitorais, ademais, têm incentivado a formação de coligações partidárias, inclusive em eleições regidas pelo sistema de representação proporcional. Isso significa que as opções eleitorais se apresentam seja como candidaturas individuais (de tal monta que impossibilita aos eleitores o acesso às informações necessárias para uma distinção mais aprimorada dos candidatos), seja como alianças eleitorais formadas por uma grande variedade de partidos.

Os problemas em torno da capacidade de o sistema propiciar um vínculo representacional relacionam-se, em grande medida, ao tamanho e à magnitude dos distritos eleitorais. Como as fronteiras das circunscrições eleitorais coincidem com as fronteiras geográficas dos Estados, cujo número de representantes (ou magnitude do distrito eleitoral) varia de acordo com o tamanho da população, torna-se difícil identificar a quem os representantes de- 
veriam prestar contas. Como assinalamos em estudo sobre os padrões de competição na disputa para as câmaras federal e dos vereadores de São Paulo (Kinzo, Martins Jr. e Borin, 2003a e b), a concentração eleitoral ou a distritalização do voto está longe de ser o padrão dominante de competição. Identifica-se uma tendência maior à dispersão e ao fracionamento do apoio eleitoral do que redutos eleitorais claramente perceptíveis. ${ }^{9}$ Em outras palavras, o estabelecimento de vínculos entre eleitores e representantes, possível quando estes possuem base eleitoral definida, não é algo generalizado. Certamente há deputados com vínculos eleitorais definidos, seja com um grupo específico (profissional, religioso etc.), seja com uma região (a exemplo dos redutos eleitorais típicos do clientelismo). Entretanto, de modo geral, os deputados desfrutam de grande autonomia em sua atividade parlamentar, o que é particularmente comum entre aqueles eleitos nas grandes cidades. O fato de a maioria dos eleitores não lembrar quem é o seu deputado ou em quem votou nas últimas eleições legislativas é uma boa indicação da inexistência de um vínculo de representação claro entre parlamentares e eleitores.

O conjunto desses fatores impede a accountability vertical efetiva, produzindo uma situação que tende a distanciar os eleitores de seus representantes. Torna-se, portanto, extremamente difícil para a população conferir responsabilidade pelo desempenho governamental. Esse talvez seja um dos fatores que contribui para aumentar a disparidade entre o sistema partidário eleitoral e o sistema partidário nas arenas decisórias, ${ }^{10}$ traço esse que já caracterizava a política partidária durante o período democrático de 1945 a 1964 (Lavareda, 1991), e que nos leva a deslocar o foco de análise para a questão partidária.

\section{Partidos, sistema partidário e democracia no Brasil}

Uma avaliação da experiência político-partidária do Brasil a partir de 1985 requer resposta para pelo menos três indagações. Em que medida os partidos brasileiros têm desempenhado um papel relevante na integração dos eleitores ao siste- ma político, mobilizando-os para participar dos pleitos e para votar em uma das opções apresentadas (partidos e/ou candidatos)? Em que medida eles oferecem opções claras e diferenciadas ao eleitor, ou seja, como têm contribuído para estruturar a escolha eleitoral e criar identidades políticas? A experiência político-partidária dos últimos dezoito anos foi capaz de produzir um padrão que possa ser consolidado no futuro?

\section{Mobilização partidária}

Uma das atividades principais dos partidos políticos é buscar apoio nas urnas. Na verdade, eles se tornaram organizações políticas em função da necessidade de mobilizar os eleitores para votar. Assim, a capacidade de o sistema partidário desempenhar esse papel revela-se pelo comparecimento eleitoral. O poder de convencimento dos partidos pode ser, portanto, medido pelo índice de participação eleitoral. No caso brasileiro, porém, o comparecimento ao pleito não é uma boa indicação de participação política, uma vez que o voto é obrigatório. Há situações, por exemplo, em que o índice de comparecimento é elevado, mas os resultados eleitorais registram um número expressivo de votos brancos e nulos. ${ }^{11}$ Isso implica que precisamos, para avaliar a capacidade dos partidos de mobilizar os eleitores, restringir o conceito de participação eleitoral à parcela de eleitores que, em uma determinada eleição, tenha expressado sua preferência por uma das opções oferecidas no pleito, isto é, o percentual da população com direito a voto que compareceu às urnas e, efetivamente, votou em um candidato ou partido. Essa conduta de análise viabiliza mostrar em que medida os partidos estariam ou não desempenhando bem uma de suas funções principais, qual seja, a de mobilizar sua base eleitoral.

A Tabela 3 mostra os percentuais de eleitores que votaram num candidato ou partido nas eleições para presidência da República, governo estadual e Câmara dos Deputados no período de 1986 a 2002. De um modo geral, as taxas de participação eleitoral no Brasil não são tão diferentes das registradas nas democracias consolidadas, onde a 
Tabela 3

Participação Eleitoral no Brasil, 1986-2002*

\begin{tabular}{|c|c|c|c|}
\hline ANO & ELEIÇÕES PRESIDENCIAIS & ELEIÇÕES PARA GOVERNADOR & Eleições para CÂMara dos Deputados \\
\hline 1986 & - & 71 & 60 \\
\hline 1990 & $80 / 78^{* *}$ & 63 & 47 \\
\hline 1994 & 66 & 60 & 48 \\
\hline 1998 & 64 & 63 & 63 \\
\hline 2002 & $75 / 76^{* * *}$ & 74 & 77 \\
\hline
\end{tabular}

*Medida pela porcentagem de votos válidos sobre a população com 18 anos ou mais.

**Dados referentes ao primeiro e segundo turno das eleições.

Fonte: Nicolau (1998a), Tribunal Superior Eleitoral e IBGE.

média foi de aproximadamente $78 \%$ nos anos de 1950, caindo para 70\% no final da década de 1990 (Dalton et al., 1984, 2000; Wattenberg, 1998). No Brasil, a taxa média de participação nas eleições presidenciais realizadas desde a redemocratização é de $73 \% .^{12}$ No entanto, os números apresentados na tabela apontam três aspectos importantes: primeiro, comparadas às eleições presidenciais, as taxas de participação nas eleições para governador e Câmara dos Deputados são muito mais baixas em 1990 e 1994 (as médias para o período são 66\% e 59\%, respectivamente); segundo, um declínio significativo nas taxas registradas nos três tipos de pleito entre 1986 e 1998 (nas eleições presidenciais, entre 1989 e 1998, a taxa caiu em 19\%, declínio semelhante (17\%) ocorreu nas eleições para governador entre 1986 e 1998); ${ }^{13}$ e, terceiro, um aumento considerável nas taxas de participação entre 1998 e 2002 nos três tipos de eleição.

Tomando esses dados como indicadores de mobilização partidária, poder-se-ia concluir que o processo de democratização no Brasil não foi acompanhado por um aumento gradual da mobilização eleitoral; pelo menos é o que apontam os dados até as eleições de 1998. No entanto, a mobilização eleitoral começou bem antes de 1985. De fato, esse foi um dos traços característicos do processo de transição democrática no Brasil, em cujos primórdios - ainda em fase de distensão do regime autoritário - a oposição conseguiu mobilizar o eleitorado contra o regime, iniciando o engajamento da população no processo eleitoral. Assim, a primeira eleição presidencial, em 1989, significou o auge do processo de mobilização. A partir daí, observa-se o declínio do engajamento político, uma vez que o jogo eleitoral democrático adquiriu um caráter rotineiro. $\mathrm{O}$ mesmo fenômeno verificou-se nas eleições para governador. No primeiro pleito, realizado em um contexto plenamente democrático (1986), a taxa de participação foi bastante elevada, declinando consideravelmente nas duas eleições seguintes. Essa tendência foi, contudo, revertida em 2002, quando as taxas de participação subiram dez pontos percentuais.

Digno de nota são os percentuais registrados para a Câmara dos Deputados, que até 1994 são bem inferiores aos registrados nos pleitos para governador e presidente. A explicação para isso tem a ver, em grande medida, com a posição central ocupada pelos cargos executivos no presidencialismo, particularmente na versão brasileira, cuja experiência é marcada por uma concentração acentuada de poder no executivo. Essa prática contribuiu para que os eleitores se acostumassem a prestar atenção muito mais nos presidentes, governadores e prefeitos do que em seus representantes parlamentares, tornando-se, pois, menos predispostos a participar das eleições legislativas. Ademais, não podemos esquecer de que o grande número de candidatos nesse tipo de pleito dificulta a tomada de decisão do eleitor, o que denota uma tendência à elevação de votos brancos e nulos em eleições legislativas 
proporcionais. No entanto, esse padrão modificou-se consideravelmente nas eleições de 1998 e 2002, quando as taxas de participação eleitoral passaram a se equiparar às registradas nos pleitos para presidente e governador (Tabela 3). É provável que o desempenho do Legislativo no processo democrático - a começar pela relevância que adquiriu durante os trabalhos da Constituinte e por seu papel no processo de impeachment do presidente Collor de Melo - possa ter contribuído para sua valorização aos olhos do eleitor, aumentando a predisposição deste a participar das eleições parlamentares. Mas esse novo padrão deve-se também a uma ação deliberada, por parte da Justiça Eleitoral, no sentido de reduzir as taxas de absenteísmo em eleições legislativas. Refiro-me à introdução de uma nova seqüência de escolha eleitoral nas urnas eletrônicas: a partir das eleições de 1998, os eleitores passaram a votar, primeiro, nos candidatos para as casas legislativas (sob o sistema de representação proporcional) e, depois, nos candidatos a presidente e governador (sob o sistema majoritário). Isso tornou imperativa a escolha de um candidato a deputado, e é provável que uma parcela substancial de eleitores tenha digitado o número correspondente ao seu candidato a governador ou a presidente quando a tela da urna eletrônica solicitava a escolha para deputado, repetindo-o novamente nas opções para os cargos executivos. Embora não se possa comprovar a ocorrência desse procedimento, é bem possível que o mecanismo criado pela Justiça eleitoral para diminuir os votos brancos e nulos nas eleições proporcionais tenha surtido efeito, mesmo porque causa estranheza o fato de nas eleições de 2002 a proporção de votos válidos para a Câmara de Deputados ter superado a registrada para governador e presidente da República.

Um segundo aspecto a ser considerado ao se analisar a questão partidária no Brasil, relaciona-se à capacidade do sistema de oferecer opções diferenciadas aos eleitores, ou seja, de estruturar a escolha eleitoral e de criar identidades partidárias. Isso nos leva ao exame da dinâmica da competição partidária e da inteligibilidade do sistema.
Fragmentação, inteligibilidade e volatilidade do sistema partidário

A despeito da controvérsia gerada em torno de a questão partidária no Brasil ser ou não um problema para a consolidação democrática, ${ }^{14}$ não há dúvida de que o sistema partidário atual é um dos mais fragmentados do mundo. Como indica a Tabela 4, o grau de fragmentação na Câmara dos Deputados, medido pelo índice de fragmentação (N) de Laakso e Taagepera (1979), ${ }^{15}$ foi de aproximadamente 3 em 1986, subiu para 9, em 1990, caiu para 8, em 1994, e para 7, em 1998, subindo novamente para 8,5 nas últimas eleições.

É certo que a dinâmica de três partidos, observada em 1986, refletia muito mais a sobrevivência de um jogo eleitoral bipartidário, que ganhou força no crepúsculo do regime militar, do que a emergência de um novo pluralismo partidário com condições de se consolidar. De forma que a fragmentação que se seguiu era esperada, especialmente em reação à camisa de força instaurada pelo bipartidarismo compulsório do regime militar. No entanto, passado este período inicial, poder-se-ia esperar uma reacomodação das forças políticas no sentido de tornar o sistema partidário mais enxuto. No entanto, a ligeira queda no índice de fragmentação partidária registrada entre 1990 e 1998 não se definiu como uma tendência, dado sua reversão em 2002. Assim, o sistema partidário continua tão fragmentado como no início da década de 1990. Além disso, como mostram os dados da Tabela 4, a intensa fragmentação não é um atributo apenas do sistema nacional de partidos; está também presente em vários Estados: treze dos 27 Estados possuem um número de partidos efetivos superior a cinco; em 22 deles os índices de fragmentação aumentaram significativamente entre 1990 e 2002.

A fragmentação do sistema partidário não seria um problema para o funcionamento da democracia caso não afetasse a inteligibilidade do processo eleitoral, isto é, a capacidade de o sistema produzir opções claras para os eleitores, permitindo-lhes escolher com base em seu conhecimento sobre os partidos ou sua identidade com eles. O problema é que no Brasil a intensa frag- 
Tabela 4

Número de Partidos Efetivos (N) por Região na Câmara dos Deputados, 1986-2002*

\begin{tabular}{|c|c|c|c|c|c|}
\hline \multirow[t]{2}{*}{ ESTADO/REGIÃO } & \multicolumn{5}{|c|}{ (N) CÂMARA DOS DepuTADOS } \\
\hline & 1986 & 1990 & 1994 & 1998 & 2002 \\
\hline Rondônia & 1,8 & 1,2 & 4,0 & 4,4 & 5,3 \\
\hline Acre & 2,0 & 1,9 & 2,5 & 4,0 & 4,0 \\
\hline Amazonas & 2,5 & 4,5 & 3,2 & 3,2 & 3,2 \\
\hline Roraima & 2,0 & 3,9 & 3,2 & 2,9 & 4,0 \\
\hline Pará & 1,6 & 4,1 & 4,0 & 5,5 & 5,3 \\
\hline Amapá & 1,6 & 3,1 & 4,0 & 4,0 & 5,3 \\
\hline Tocantins & - & 2,8 & 4,0 & 3,5 & 4,0 \\
\hline Maranhão & 2,5 & 5,5 & 3,9 & 5,5 & 4,6 \\
\hline Piauí & 2,6 & 2,9 & 3,3 & 2,8 & 3,8 \\
\hline Ceará & 2,5 & 5,1 & 3,1 & 1,7 & 4,7 \\
\hline Rio Grande do Norte & 2,4 & 3,1 & 2,2 & 2,5 & 4,0 \\
\hline Paraíba & 2,2 & 4,2 & 2,4 & 3,8 & 6,5 \\
\hline Pernambuco & 2,1 & 3,6 & 3,4 & 4,4 & 7,2 \\
\hline Alagoas & 2,5 & 3,5 & 7,5 & 7,5 & 5,4 \\
\hline Sergipe & 2,4 & 2,8 & 4,6 & 6,3 & 6,4 \\
\hline Bahia & 2,2 & 6,6 & 4,6 & 3,3 & 3,5 \\
\hline Minas Gerais & 2,0 & 7,4 & 6,8 & 6,5 & 8,6 \\
\hline Espirito Santo & 1,8 & 2,1 & 5,0 & 4,5 & 7,1 \\
\hline Rio de Janeiro & 5,0 & 4,9 & 9,9 & 6,7 & 9,5 \\
\hline São Paulo & 3,6 & 7,4 & 6,8 & 7,1 & 7,8 \\
\hline Paraná & 1,4 & 5,5 & 7,1 & 6,0 & 6,8 \\
\hline Santa Catarina & 2,4 & 4,1 & 4,4 & 5,0 & 4,1 \\
\hline Rio Grande do Sul & 2,7 & 4,1 & 5,4 & 5,7 & 6,4 \\
\hline Mato Grosso Sul & 2,4 & 3,9 & 4,6 & 5,2 & 4,0 \\
\hline Mato Grosso & 2,0 & 3,5 & 8,0 & 4,0 & 4,6 \\
\hline Goiás & 1,8 & 4,5 & 4,6 & 3,7 & 4,6 \\
\hline Distrito Federal & 2,4 & 5,2 & 4,0 & 5,2 & 4,0 \\
\hline Brasil & 2,9 & 9,0 & 8,2 & 7,2 & 8,5 \\
\hline
\end{tabular}

*Agradeço a Maria do Socorro Braga pela coleta dos dados para esta tabela. Fonte: LEEX, Iuperj.

mentação partidária está acompanhada por uma pequena inteligibilidade do processo eleitoral. Em geral, um sistema partidário fragmentado tende a ter partidos de contornos mais definidos, alicerçados em algum tipo de clivagem social, regional ou política, proporcionando aos eleitores opções mais estruturadas e diferenciadas na disputa eleitoral. Isso não é o que ocorre no caso brasileiro, dado que a maioria dos partidos, como organizações distintas, não possui contornos claramente definidos. Isso não significa negar a existência de diferenças entre eles no plano ideológico, como vários estudos indicaram ao dispor os partidos num continuum esquerda-direita (Kinzo, 1989, 1993; Lamounier, 1989; Rodrigues, 1987, 2002; Fi- gueiredo e Limongi, 1999). No entanto, trata-se mais de gradações ou variações do que propriamente diferenças estruturais.

Disso decorre a facilidade com que os candidatos eleitos migram para outro partido sem nenhum constrangimento ${ }^{16}$ - o que denota, aliás, a fragilidade dos partidos, no sentido de que não são organizações relevantes o suficiente para manter seus próprios quadros. Evidência mais forte é o fato de os partidos raramente se engajarem nas disputas eleitorais como atores distintos; apresentam-se, ao contrário, em alianças partidárias. Ou seja, os competidores do jogo eleitoral não são os partidos como unidades diferenciadas, mas candidatos e coligações formadas por diversos partidos, não raro de diferentes orientações ideológicas. 
Pode-se argumentar que, em um contexto de multipartidarismo e de eleições majoritárias para os cargos executivos, é natural que os partidos formem alianças, principalmente em se tratando de eleições nacionais - como são as presidenciais em um país com as dimensões do Brasil. Mas, as coligações são prática disseminada em todos os níveis - do nacional ao municipal. Tanto nas eleições para governo de Estado como para prefeitura municipal, todos os partidos, independentemente de sua dimensão ou linha ideológica, recorrem às coligações. Além disso, esse recurso é utilizado também nas eleições legislativas sob o sistema de representação proporcional, o qual se destina, justamente, a garantir a representação das minorias que, por sua vez, desejam se diferenciar dos grandes partidos.

A prática da coligação, evidentemente, se torna necessária em virtude da fragmentação do sistema partidário. Mas isso faz com que o sistema permaneça fragmentado, já que é permitido aos políticos e aos partidos formarem tais alianças. Em outras palavras, as estratégias eleitorais são construídas de forma a obter o melhor resultado no contexto institucional em que os políticos operam. A formação de alianças constitui, pois, a melhor estratégia tanto para os grandes partidos como para os pequenos. De um lado, ao se coligar com um grande partido que lança uma candidatura ao governo do Estado, os pequenos partidos garantem sua participação na coligação para as eleições proporcionais, aumentando suas chances de conquistar uma cadeira na Câmara dos Deputados ou nas assembléias legislativas. De outro, ao se aliar aos pequenos, os grandes partidos aumentam seus recursos eleitorais (o que inclui tempo maior de propaganda eleitoral no rádio e na televisão) e, portanto, suas chances de vencer a eleição majoritária. Em contrapartida, sua chance de eleger uma grande bancada no legislativo torna-se mais restrita, pois ao concorrerem nas eleições legislativas em uma lista de candidatos coligados (não previamente ordenados) os grandes partidos abrem espaço para os candidatos bem votados dos pequenos partidos da coligação.

Se para os políticos e os partidos esta é, sem dúvida, a estratégia mais racional, seu impacto so- bre os eleitores está longe de ser positivo, uma vez que se vêem diante de uma disputa em que atores partidários não são claramente distintos, isto é, entidades que constroem alternativas eleitorais e identidades. Em outras palavras, torna-se difícil para o eleitor identificar e distinguir os partidos em disputa: são muitos os partidos, muitas as alianças eleitorais, cuja composição varia de um lugar para o outro e de uma eleição para outra. Ademais, a disputa eleitoral põe em evidência muito mais os candidatos do que os partidos. Em suma, a intensa fragmentação e a falta de nitidez do sistema partidário fazem com que os eleitores tenham dificuldade em fixar os partidos, distingui-los e, assim, conseguir criar identidades partidárias. ${ }^{17}$

Uma conseqüência visível desse processo é a volatilidade eleitoral - dimensão importante da estabilidade do sistema partidário (Pedersen, 1990; Bartolini e Mair, 1990). Quanto menor a inconstância, maior a probabilidade de as siglas partidárias desempenharem mais plenamente na arena eleitoral sua função de determinar as preferências eleitorais independentemente do apelo de algum candidato particular, de posições políticas pontuais ou de acontecimentos inesperados. A institucionalização do sistema partidário dificilmente pode ocorrer em contextos de grande volatilidade eleitoral. Seria esse o caso no Brasil?

Entre as democracias consolidadas, os níveis de volatilidade, segundo o índice de Pedersen, variam de um país para outro, mas raramente atingem as cifras elevadas do Brasil. ${ }^{18}$ Os dados apresentados por Nicolau (1998a) indicam que no período de 1982 a 1998, em média, cerca de 30\% do eleitorado brasileiro mudou seu voto de um partido para outro em eleições consecutivas. Uma análise mais detalhada a esse respeito encontra-se em Braga (2003): os índices para a Câmara dos Deputados (reproduzidos na Tabela 5) foram calculados com base nos resultados eleitorais por município, e são apresentadas as médias por Estado nos três pares de eleições no período de 1990 a 2002. O exame desses dados nos revela, primeiro, que os valores são bastante elevados nas eleições ocorridas entre 1990 e 1994. De fato, o nível de instabilidade do sistema partidário alcançou seu ápice em 1990, o que era reflexo das mudan- 
ças por que passaram os partidos durante o período de elaboração dos trabalhos da Assembléia Constituinte (1987-1988) - por exemplo, a criação do PSDB a partir de uma dissidência do PMDB e a reorganização do PDS após uma fusão com dois outros partidos. Em segundo, tomando como parâmetro a média total dos valores dos Estados, verifica-se que o índice de volatilidade decresceu entre 1994 e 1998 (de 46,2 para 40,4), mas se manteve inalterado entre 1998 e $2002(40,1)$. Ou seja, o índice de volatilidade estabilizou-se em um nível bastante elevado. Em terceiro, observa-se que esse índice varia consideravelmente de um Estado para outro, independentemente do tamanho de seu eleitorado, ${ }^{19}$ e, em alguns Estados, aumentou. Esse crescimento deve ter a ver com o fato de alguns partidos terem conseguido se expandir nacionalmente, mudando, assim, a dinâmica eleitoral anteriormente estabelecida em alguns Estados. A manutenção de um número bastante elevado de partidos na competição política, obriga-os a se expandir nacionalmente, expansão que ainda se encontra em processo, o que significa que a volatilidade deverá se manter elevada. Ou seja, ainda não se estabeleceu no Brasil um padrão definitivo de apoio partidário. O sistema partidário brasileiro está, portanto, distante de uma consolidação.

Tabela 5

Volatilidade Eleitoral Partidária, Câmara dos Deputados (1990/2002)

\begin{tabular}{|c|c|c|c|c|}
\hline ESTADOS & 1990-1994 & 1994-1998 & 1998-2002 & MÉDIA \\
\hline $\mathrm{AC}$ & 29,3 & 60,4 & 48,3 & 46 \\
\hline $\mathrm{AL}$ & 76,1 & 44,7 & 43,3 & 54,7 \\
\hline $\mathrm{AM}$ & 70,7 & 69,1 & 37,1 & 58,9 \\
\hline $\mathrm{AP}$ & 43,7 & 26,1 & 36,3 & 35,3 \\
\hline BA & 52,6 & 37,9 & 30,9 & 40,5 \\
\hline $\mathrm{CE}$ & 41,5 & 27 & 31,9 & 33,5 \\
\hline DF & 30,1 & 39,1 & 25,7 & 31,6 \\
\hline ES & 43,8 & 48,6 & 45,4 & 45,9 \\
\hline GO & 47,5 & 33,7 & 47,1 & 42,7 \\
\hline MA & 53,9 & 41,6 & 36,8 & 44,1 \\
\hline MG & 50 & 36 & 43,8 & 43,3 \\
\hline MS & 56,2 & 43,4 & 45 & 48,2 \\
\hline MT & 53,1 & 44,4 & 42,6 & 46,7 \\
\hline PA & 40,8 & 46,5 & 34,8 & 40,7 \\
\hline PB & 38,9 & 35,9 & 45,6 & 40,1 \\
\hline PE & 33,4 & 35,9 & 38,7 & 36 \\
\hline PI & 39,9 & 33,1 & 30,8 & 34,6 \\
\hline PR & 54,1 & 41,9 & 47,3 & 47,8 \\
\hline RJ & 45,3 & 30,9 & 35,3 & 37,2 \\
\hline $\mathrm{RN}$ & 39,1 & 38,1 & 34,4 & 37,2 \\
\hline $\mathrm{RO}$ & 66,9 & 47,9 & 43,1 & 52,6 \\
\hline $\mathrm{RR}$ & 35,5 & 53,1 & 79,2 & 55,9 \\
\hline RS & 29,4 & 23,1 & 26,5 & 26,3 \\
\hline SC & 29 & 29,4 & 27,8 & 28,7 \\
\hline SE & 47,5 & 46,5 & 46,2 & 46,7 \\
\hline SP & 33 & 36,2 & 36,0 & 35 \\
\hline TO & 67,4 & 41,2 & 42,4 & 50,3 \\
\hline MÉDIA & 46,2 & 40,4 & 40,1 & 42,2 \\
\hline DES. PADR̃̃O & 13,1 & 10,2 & 10,3 & 8,4 \\
\hline$M A X$ & 59,4 & 50,6 & 50,4 & 50,6 \\
\hline MIN. & 33,1 & 30,2 & 29,7 & 33,9 \\
\hline
\end{tabular}

*Reproduzido de Braga (2003).

Fonte: TSE, TRE-BA, TRE-SP, TRE-SE, TRE-MA, TRE-RO e TRE-TO. 


\section{Considerações Finais ${ }^{20}$}

Observando o período de mais de dezoito anos de experiência democrática no Brasil, podese afirmar que a via eleitoral e a saída constitucional se afirmaram como caminho de alternância no poder e de resolução dos impasses políticos. E a eleição presidencial de 2002 foi certamente um marco no processo de consolidação da democracia. Isso, não apenas pelo que representou a eleição de Lula para presidente da República (um líder político de esquerda, oriundo das camadas populares), como também pelo fato de ter ascendido ao poder um partido de peso na arena política que ainda não havia sido eleito para o poder executivo em âmbito nacional. Completa-se, portanto, o ciclo de consolidação democrática no Brasil ao se ultrapassar todos os possíveis obstáculos à livre e efetiva alternância no poder. ${ }^{21}$

Desse modo, podemos afirmar com segurança que eleições e democracia estão asseguradas no Brasil. O que dizer, no entanto, da temática relativa aos partidos e ao sistema partidário e sua relação com a consolidação democrática? A esse respeito, contudo, não se pode afirmar que o avanço tenha sido considerável.

O cenário partidário aqui delineado - marcado por intensa fragmentação, fragilidade partidária, baixa inteligibilidade da disputa eleitoral e elevada volatilidade eleitoral - são evidências de que, ao longo desses dezoito anos de democracia, os avanços em direção à consolidação do sistema partidário foram bastante modestos. De modo que, a despeito de as eleições do último ano terem sido um marco na consolidação da democracia, o evento democrático que delas resultou - ascensão de um novo governo, apoiado por um partido de esquerda - está longe de significar um passo decisivo rumo ao fortalecimento do sistema partidário.

Primeiro porque o resultado da disputa para os governos estaduais e para as casas legislativas reproduziu, em grande medida, o quadro anterior, caracterizado por uma elevada fragmentação de poder: nada menos que dezenove partidos conseguiram representação na Câmara (sete deles com representação superior a 5\%, mas nenhum com força parlamentar superior a $18 \%$ ), e oito partidos diferentes elegeram governadores de Estado. Essa situação torna imperativos a formação de um governo de coalizão bastante heterogêneo, porque formado por inúmeros partidos, e a ampliação artificial da representação partidária de forma a fortalecer uma base aliada. Não é mero acaso que o governo Lula tenha formado uma coalizão ainda mais ampla do que a do governo anterior - dez partidos fazem parte da base do governo.

Segundo porque foi reeditado, já no início do novo governo, o fenômeno de "troca-troca partidário" na direção da base aliada. Assim, parlamentares recém-eleitos por um partido migram para outro sem qualquer constrangimento. Apenas como indicativo, até outubro de 2003, 11\% dos deputados encontravam-se filiados a um partido diferente daquele que os elegeu..$^{22}$ Se considerarmos que apenas quatro partidos conseguiram eleger uma bancada com mais de 10\% das cadeiras na Câmara, esse remanejamento tem efeito considerável na correlação de forças no Parlamento e, acima de tudo, no peso relativo dos parceiros da coalizão governamental. ${ }^{23}$

Assim, o que parecia a emergência de um novo alinhamento governo/oposição - assumindo o poder aqueles que dele estavam alijados tornou-se uma situação sem contornos nítidos, em que partidos ligados ao governo anterior passaram a integrar a nova coalizão, e antigos adversários ideológicos passaram a compartilhar o mesmo bloco.

A despeito desses problemas no front partidário, o governo Lula construiu sua base de apoio parlamentar com sucesso, e tem conseguido, até o presente, administrá-la satisfatoriamente, garantindo sua governabilidade, o que também ocorreu na gestão de Fernando Henrique Cardoso. Ademais, o fato de os partidos políticos mostrarem-se incapazes de manter seus representantes eleitos não tem suscitado qualquer questionamento quanto a uma possível crise de representação.

Em vista desse quadro podemos questionar até que ponto o fortalecimento do sistema partidário é realmente um fator fundamental na consolidação da democracia brasileira.

Essa indagação é ainda mais pertinente se levarmos em consideração o que tem ocorrido 
nas democracias consolidadas. A problemática partidária nas chamadas "velhas" democracias tem sido ampla e profundamente examinada na literatura internacional. ${ }^{24} \mathrm{O}$ intenso debate nos últimos trinta ou quarenta anos sobre as novas tendências nas atitudes e nos comportamentos políticos, que criam formas alternativas de participação, tem questionado a centralidade da instituição "partido político". Baixas taxas de mobilização e participação, filiações partidárias em declínio e avaliações negativas das instituições de representação são tendências há muito presentes nas democracias consolidadas. Não obstante a controvérsia a respeito da extensão e do significado de tais transformações, o fato é que elas indicam que os papéis desempenhados pelos partidos deixaram de ter a centralidade de outrora, ou esses papéis foram, de fato, substituídos por outros.

É necessário, então, que reflitamos nesse contexto peculiar as perspectivas da política partidária na democracia brasileira. De fato, no período de experiência democrática pós-regime militar, o Brasil tem enfrentado uma situação paradoxal, qual seja, a de consolidar instituições partidárias que, a despeito do papel fundamental que desempenharam na consolidação das democracias ocidentais, deixaram de ocupar a posição central que ocupavam no sistema político. Talvez Philippe Schmitter (2001) tenha razão quando argumenta, ao se referir à presente experiência políticopartidária na América Latina, que a existência de sistemas partidários pouco consolidados não necessariamente resulta em democracias não consolidadas. Por não mais desempenharem as mesmas funções das quais resultaram sua força no passado nas "velhas" democracias, os partidos perderam a centralidade a ponto de não constituírem mais um fator fundamental para a consolidação das novas democracias. Conclui Schmitter:

[...] o que parece mais provável é que as novas democracias, como as várias antigas democracias, terão de sobreviver com muito menos agregação e intermediação que no passado. Seus partidos políticos produzirão muito menos estruturação eleitoral, identificação simbólica, governança partidária e agregação de interesses do que seus predecessores. O que isso implica para a qualidade dessas novas democracias é uma outra questão! (2001, pp. 86-87).

As implicações para a qualidade da democracia, estão, no entanto, no terreno normativo. Embora essa possa ser uma discussão pouco afeita ao debate que hoje domina a ciência política brasileira, não há por quê evitá-lo. Além disso, não se conhece, até o momento, meios alternativos de construção e consolidação de uma forma democrática de convivência política capazes de substituir os mecanismos institucionais que foram os pilares das democracias ocidentais.

\section{NOTAS}

1 Nas palavras de Schumpeter, "o método democrático é aquele arranjo institucional para se chegar a decisões políticas em que os indivíduos adquirem o poder de decidir por meio de uma luta competitiva pelo voto da população" (1976, p. 269).

2 A controvérsia entre democracia política e democracia social é bem conhecida. Essa questão foi bastante debatida durante os primeiros anos de redemocratização no Brasil (ver, em especial, Reis e O'Donnell (1988), e sempre ressurge quando se examina as experiências atuais das chamadas democracias emergentes. Ainda que não seja nossa intenção enveredar para as argumentações e as implicações dessa controvérsia, convém fazer uma observação: é certo que o conceito estrito de democracia, baseado nas regras procedimentais, deixa de considerar a questão da desigualdade social e o conseqüente acesso desigual ao chamado mercado político. Mas é verdade, também, que pensar a democracia em termos abrangentes, como querem os defensores da democracia social, destitui do conceito a propriedade de distinguir um regime democrático de um regime autoritário ou totalitário. Em função dessa característica, Sartori formulou sua definição de democracia como sendo, antes de tudo, "um sistema no qual ninguém pode escolher a si mesmo, investir-se do poder de governar e, portanto, nin- 
guém pode arrogar para si um poder incondicional e ilimitado" (Sartori, 1987, p. 206).

3 Emprego a definição estrutural de partidos, contida no trabalho de Panebianco (1988).

4 Vale lembrar que no Brasil o voto é obrigatório.

5 No sentido de que seus direitos de cidadania não estão plenamente garantidos. Sobre os problemas de cidadania no Brasil, ver Carvalho (2001).

6 A despeito de suas posições radicais e formas de ação questionáveis, a mobilização do MST não só tem mantido o tema da reforma agrária na agenda do governo, mas também instituiu uma forma diferente de relacionamento com o Estado. Citando a excelente análise de Martins sobre o MST e a reforma agrária, o que existe de inovador nas relações entre o MST e o Estado é o fato de este não agir preventivamente para neutralizar as tensões sociais, mas agir em resposta às iniciativas e às pressões da sociedade. Martins conclui: "[esta é] uma mudança politicamente importante que inverteu o processo típico, que aqui no Brasil fez do Estado o criador da sociedade civil" (Martins, 1999, p. 121).

7 Refiro-me à accoutability vertical e não horizontal. A esse respeito ver, em especial, O’Donnell (1998).

8 Em oito Estados são mais de vinte partidos, e, em dois deles, mais de cinqüenta.

9 Discordamos, portanto, da tese defendida por Ames (1995), Mainwaring (1991) e Pereira e Rennó (2001) de que, de um modo geral, os deputados controlam determinada área mediante benefícios clientelistas, uma vez que esses autores se apóiam no pressuposto de que os parlamentares brasileiros, todos eles, seriam representantes de distritos informais, o que nem sempre é o caso.

10 A esse respeito ver, em especial, as importantes observações de Lima Jr. (1993).

11 Esse foi particularmente o caso das eleições realizadas sob o regime militar. Por exemplo, nas eleições de 1970, os percentuais de votos brancos e nulos ultrapassaram o percentual de votos no partido da oposição (cf. Kinzo, 1988).

12 Optamos por considerar como eleitorado a parcela da população maior de 18 anos, já que entre 16 e 18 anos a inscrição e o voto não são obrigatórios. Os números sobre população acima de 18 anos são estimativas para os anos de 1986, 1994, 1998 e 2002, levantadas pelo IBGE - Instituto Brasileiro de Geografia e Estatística.

13 Diferenças marcantes entre regiões e entre Estados indicam que a capacidade de os partidos mobilizarem os eleitores também varia consideravelmente de um Estado para o outro. De qualquer maneira, as taxas de participação eleitoral diminuíram neste período em todo o país.

14 A esse respeito ver, principalmente, Lamounier e Meneguello (1986); Kinzo (1993); Mainwaring (1995, 1999) e Figueiredo e Limogi (1999). Uma boa síntese deste debate encontra-se em Rodrigues (2002).

15 O número efetivo de partidos é calculado por $\mathrm{N}=1 /$ (1-Âpi2 ), onde $p$ é a proporção de votos obtidos por cada partido para a Câmara dos Deputados. Sobre o índice de fragmentação, ver também Rae (1975).

16 Sobre o fenômeno da migração partidária, ver, em especial, Melo (2000).

17 Vale salientar, porém, que há pelo menos dois dispositivos que podem, a longo prazo, ajudar os partidos a fixarem suas siglas junto ao eleitor. Referi-mo-nos, em primeiro lugar, à identificação dos partidos e de seus respectivos candidatos por meio de números usados para votar na urna eletrônica. Como no caso dos partidos os números são permanentes, estes podem fortalecer uma associação entre número e partido, a qual poderia prevalecer sobre a coligação. Em segundo, os partidos têm direito a uma hora de propaganda gratuita no rádio e na televisão para divulgar sua imagem, duas vezes por ano. Nessas ocasiões são destacados os partidos e seus líderes principais. 
18 A média do índice Pederson para os países da Europa, entre 1985 e 1996, foi 11,0 (cf. Nicolau, 1998b). Sobre volatilidade eleitoral, ver, em especial, Bartolini e Mair (1990) e Mair (1997).

19 Essa variação é também grande entre diferentes grupos de municípios. De acordo com os dados de Braga (2003), curiosamente, os índices são mais elevados nas categorias de cidades média e pequena do que nas cidades grandes e capitais de Estado.

20 Parte da discussão exposta nesta sessão foi apresentada na mesa redonda "Eleições, partidos e governos no Cone Sul: Argentina, Brasil, Chile e Uruguai", do XXVII Encontro Anual da Anpocs, Caxambu, 21-25 out. 2003.

21 Isso não significa que anteriormente não tenha havido alternância no poder. Na verdade, alternância e incerteza eleitoral são traços característicos do processo de democratização no Brasil, pois tanto o primeiro como o segundo presidente eleito diretamente (Collor e Fernando Henrique Cardoso) não são provenientes de partidos que dominaram inicialmente o jogo político da Nova República, embora houvesse, de alguma forma, uma linha de continuidade - no caso de Collor, seus vínculos políticos com a oligarquia nordestina; no caso de FHC, seus vínculos políticos originários do MDB/PMDB. A diferença da eleição de 2002 foi o fato de a alternância ter se dado com um partido que até então estivera alijado totalmente do poder nacional, embora tivesse se apresentado como principal competidor em todos os embates anteriores.

22 De acordo com a distribuição das bancadas partidárias fornecida pela Câmara dos Deputados em 15/10/2003.

23 Note-se que, menos de um ano após a eleição, o PTB teve sua bancada engrossada em $100 \%$ (de 26 passou para 53 deputados). O PL aumentou de 26 para 42 deputados; o PFL diminuiu sua bancada de 84 para 67 e o PSDB, de 71 para 51
24 A esse respeito a bibliografia é bastante ampla. Entre os trabalhos mais importantes, destacam-se Kirchheimer (1966), Lawson e Merkl (1988), Katz e Mair (1994), Mair (1997), Wattenberg (1998), Broughton e Donovan (1999), Dalton et al. (2000) e Diamond e Gunther (2001).

\section{BIBLIOGRAFIA}

AMES, Barry. (1995), "Electoral rules, constituency pressures, and Pork Barrel: bases of voting in the Brazilian congress". The Journal of Politics, 5 (2): 324-343.

BARTOLINI, S. \& MAIR, P. (1990), Identity, competition and electoral availability: the stabilisation of European electorates, 1885-1985.Cambridge, Cambridge University Press.

BRAGA, Maria do Socorro S. (2003), O processo partidário-eleitoral brasileiro: padrões de competição política (1982-2002). Tese de doutorado, São Paulo, Universidade de São Paulo (mimeo.).

BRANDÃO, Gildo M. (1997), "A ilegalidade mata: o partido comunista e o sistema partidário (1945-1964)". Revista Brasileira de Ciências Sociais, 12 (33): 23-34.

BROUGHTON, D. \& DONOVAN, M. (eds.). (1999), Changing party systems in Western Europe. Londres, Pinter.

CARVALHO, José Murilo de. (2001), Cidadania no Brasil: o longo caminho. Rio de Janeiro, Civilização Brasileira.

CHILCOTE, Ronald. (1982), Partido comunista brasileiro: conflito e integração, 19221972. Rio de Janeiro, Graal.

DAHL, Robert. (1971), Poliarchy: participation and opposition. New Haven, Yale University Press.

DALTON, R. J.; MCLLISTER, I. \& WATTENBERG, M. (2000), "The consequences of partisan dealignment", in R. J. Dalton e M. Wattenberg (eds.), Parties without parti- 
sans: political change in advanced industrial democracies, Oxford, Oxford University Press.

DALTON, Russel; FLANAGAN, Scott \& BECK, Paul (eds.). (1984), Electoral change in advanced industrial democracies: realignment or realignment? Princeton, Princeton University Press

DIAMOND, Larry \& GUNTHER, Richard (eds.). (2001), Political parties and democracy. Baltimore/Londres, The Johns Hopkins University Press

FIGUEIREDO, Argelina \& LIMONGI, Fernando. (1999), Executivo e legislativo na nova ordem constitucional. São Paulo, FGV.

KATZ, Richard S. \& MAIR, Peter (eds.). (1994), How parties organize: change and adaptation in party organizations in Western democracies. Londres, Sage Publications.

KINZO, Maria D’Alva G. (1980), Representação politica e sistema eleitoral no Brasil. São Paulo, Símbolo.

. (1989), "O quadro partidário e a Constituinte". Revista Brasileira de Ciência Politica, 1 (1): 91-124.

(1993), Radiografia do quadro partidário brasileiro. São Paulo, Fundação Konrad-Adenauer-Stiftung.

(1988), Oposição e autoritarismo: gênese e trajetória do MDB, 1966-1979. São Paulo, Vértice/Idesp.

(2001), "Transitions: Brazil", in M. A. Garretón e E. Newman (eds.), Democracy in Latin America: (re)constructing political society. Tokyo, United Nations University Press.

KINZO, M. D. \& DUNKERLEY, James. (2003), Brazil since 1985: economy, polity and society. Londres, Institute of Latin American Studies.
KINZO, M. D.; MARTINS JR., J. P. \& BORIN, I. (2003a), "Padrões de competição eleitoral na disputa para a Câmara paulistana (1992-2000)". Revista Novos Estudos, 65.

(2003b), " Padrões de competição eleitoral na disputa para a Câmara dos Deputados (1994-2002)". Trabalho apresentado no VI Congresso de Ciencia Política y de la Administración, Asociación Española de Ciencia Politica y de la Administración, Barcelona, 18-20 set. 2002.

KIRCHHEIMER, O. (1966), "The transformation of the Western European party systems", in Joseph Lapalombara e Myron Weiner (eds.), Political parties and political development, Princeton, Princeton University Press.

LAAKSO, Markku \& TAAGEPERA, Rein. (1979), "Effective number of parties: a measure with applications to West Europe". Comparative Political Studies, 12: 3-27.

LAMOUNIER, Bolívar. (1980), "A representação proporcional no Brasil: mapeamento de um debate". Revista de Cultura e Política, 7: 5-42.

(1989), Partidos e utopias: o Brasil no limiar dos anos 90. São Paulo, Edições Loyola.

LAMOUNIER, B. \& MENEGUELLO, Rachel. (1986), Partidos politicos e consolidação democrática. São Paulo, Brasiliense.

LAWSON, Kay \& MERKL, Peter (eds.). (1988), When parties fail: emerging alternative organizations. Princeton, Princeton University Press.

LAVAREDA, Antônio. (1991), A democracia nas urnas: o processo partidário-eleitoral brasileiro. Rio de Janeiro, Iuperj/Rio Fundo Editora.

LIMA JR., Olavo Brasil. (1993), Democracia e instituições políticas no Brasil dos anos 80. São Paulo, Edições Loyola.

MAINWARING, Scott. (1991), "Políticos, partidos e sistemas eleitorais: o Brasil numa pers- 
pectiva comparada". Novos Estudos, 29: 34-58.

(1995), "Brazil: weak parties, feckless democracy", in S. Mainwaring e T. Scully (eds.), Building democratic institutions: party systems in Latin America, Stanford, Stanford University Press.

(1999). Rethinking party systems in the third wave of democratization: the case of Brazil. Stanford, Stanford University Press.

MAIR, Peter. (1997), Party system change: approaches and interpretations. Oxford, Clarendon Press.

MARTINS, José de Souza. (1999), "Reforma agrária: o impossível diálogo sobre a história possível". Tempo Social, Revista de Sociologia da USP, 11 (2): 97-128.

MELO, Carlos Ranulfo F. (2000), "Por que mudam de partidos os deputados brasileiros?", Teoria e Sociedade, 6:122-177.

NICOLAU, Jairo M. (1996), Multipartidarismo e democracia. Rio de Janeiro, FGV Editora.

(1997), "As distorções na representação dos Estados na Câmara dos Deputados brasileira". Dados, 40 (3): 441-464.

. (1998a), "A volatilidade eleitoral nas eleições para a Câmara dos Deputados brasileira (1982-1994). Trabalho apresentado no XXII Encontro Anual da Anpocs, Caxambu.

(1998b), Dados eleitorais do Brasil: 1982-1996. Rio de Janeiro, Revan.

O'DONNELL, Guillermo. (1998), “Accountability horizontal e novas poliaquias". Lua Nova, 44: 27-54.

PANEBIANCO, Angelo. (1988), Political parties: organisation and power. Cambridge, Cambridge University Press.

PEDERSEN, Mogens. (1990), "Electoral volatility in Western Europe: 1948-1977", in Peter Mair (ed.), The West European party system, Oxford, Oxford University Press.
PEREIRA, Carlos \& RENNÓ, Lucio. (2001), "O que é que o reeleito tem? Dinâmicas políticoinstitucionais locais e nacionais nas eleições de 1998 para a Câmara dos Deputados". Revista Dados, 44 (2): 323-362.

PERES, Paulo Sérgio. (2002), "Sistema Partidário e instabilidade eleitoral no Brasil', in C. R. J. Pinto e A. M. Santos (eds.), Partidos no Cone Sul, Rio de Janeiro, Fundação Konrad Adenauer.

RAE, Douglas W. (1975), The political consequences of electoral laws. 2 ed. New Haven, Yale University Press.

REIS, Fábio Wanderley \& O'DONNELL, Guillermo (eds.). (1988), A democracia no Brasil: dilemas e perspetivas. São Paulo, Vértice.

RODRIGUES, Leoncio Martins. (1987), Quem é quem na Constituinte: uma análise sociopolítica dos partidos e deputados. São Paulo, Oesp-Maltese.

(2002), Partidos, ideologia e composição social. São Paulo, Edusp.

SARTORI, Giovanni. (1987), Theory of democracy revisited. Chatham, Chatham House.

SCHMITTER, Philippe. (2001), "Parties are not what they once were", in Larry Diamond e Richard Gunther (eds.), Political parties and democracy, Baltimore/Londres, The Johns Hopkins University Press.

SCHUMPETER, Joseph. (1976), Capitalism, socialism and democracy. 5 ed. Londres, George Allen \& Unwin.

SOARES, Glaucio A. D. (1971), "El sistema electoral y representación de los grupos sociales en Brasil, 1945-1962". Revista Latinoamericana de Ciencia Politica, 2 (1):5-23.

WATTENBERG, Martin. (1998), The decline of American political parties, 1952-1996. Cambridge, Harvard University Press. 


\section{PARTIDOS, ELEIÇÕES E DEMOCRACIA NO BRASIL PÓS-1985}

\author{
Maria D'Alva G. Kinzo
}

\section{Palavras-chave}

Partidos políticos; Eleições; Democracia; Instituições políticas brasileiras.

Este artigo discute a relação entre partidos, eleições e democracia no contexto brasileiro atual. A preocupação principal é examinar em que medida a experiência democráticoeleitoral em vigor desde 1985 tem contribuído para a consolidação dos partidos, do sistema partidário e da democracia no Brasil. Para estabelecer os parâmetros da análise, definimos, em primeiro lugar, o significado utilizado dos termos "partidos", "eleições" e "democracia". Em segui$\mathrm{da}$, analisamos a experiência eleitoral recente, salientando seu papel primordial no sentido de assegurar condições mínimas de uma polity democrática. Por fim, discutimos a experiência partidária atual, suas principais características e problemas. Empreende-se na conclusão uma breve reflexão a respeito da relação entre as experiências eleitoral e partidária e a consolidação da democracia no Brasil.

\section{PARTIES, ELECTIONS, AND DEMOCRACY IN BRAZIL AFTER 1985}

\author{
Maria D'Alva G. Kinzo
}

\section{Keywords}

Political parties; Elections; Democracy; Brazilian political institutions.

The article discusses the relationship among parties, elections, and democracy in the Brazilian current context. The main concern is examining how much the democratic and electoral experience has contributed to the consolidation of parties, party system, and democracy in Brazil since 1985. It defines the meanings of "party," "elections," and "democracy" in order to establish analysis parameters. It then analyses the recent electoral experiences highlighting its primordial role in assuring minimal conditions for a democratic polity. It finally discusses the current party experience, as well as its main aspects and problems. It concludes with a brief reflexion on the relationship between both the electoral and party experience and the consolidation of democracy in Brazil.

\section{PARTIS, ÉLECTIONS ET DÉMOCRATIE AU BRÉSIL DANS L'APRÈS 1985}

\author{
Maria D'Alva G. Kinzo
}

\author{
Mots-clés \\ Partis politiques; Élections; \\ Démocratie; Institutions poli- \\ tiques brésiliennes.
}

Cet article aborde la relation entre les partis, les élections et la démocratie dans le contexte brésilien actuel. Notre principale inquiétude est d'examiner dans quelle mesure l'expérience démocratique et électorale en vigueur depuis 1985 a contribué à la consolidation des partis, au système des partis et à la démocratie au Brésil. Pour établir ces paramètres d'analyse, nous avons défini, en premier lieu, la signification employée pour les termes "partis", "élections" et "démocratie". Ensuite, nous avons analysé l'expérience électorale récente, en mettant en avant son rôle primordial dans le sens d'assurer les conditions minimales pour une polity démocratique. Finalement, nous analysons l'expérience actuelle du système des partis, ses principaux problèmes et caractéristiques. Nous proposons, en guise de conclusion, une brève réflexion à propos des rapports entre les expériences électorales et du système des partis et la consolidation de la démocratie au Brésil. 